\title{
Patternable Poly(chloro-p-xylylene) Film with Tunable Surface Wettability Prepared by Temperature and Humidity Treatment on a Polydimethylsiloxane/Silica Coating
}

\author{
Yonglian Yu ${ }^{1,2}$, Hong Shao ${ }^{2}$, Zhoukun He ${ }^{2, *(1)}$, Changyu Tang ${ }^{2}$, Jian Yang ${ }^{2}$, Yongsheng $\mathrm{Li}^{2,3}$, \\ Cong Wang ${ }^{2}$, Xiuyun $\mathrm{Li}^{1, *}$, Maobing Shuai ${ }^{3}$ and Jun Mei ${ }^{2}$ \\ 1 State Key Laboratory Cultivation Base for Nonmetal Composites and Functional Materials, \\ School of Materials Science and Engineering, Southwest University of Science and Technology, \\ Mianyang 621010, China; Yonglian_Yu@163.com \\ 2 Chengdu Green Energy and Green Manufacturing Technology R\&D Center, \\ Chengdu Development Center of Science and Technology, China Academy of Engineering Physics, \\ Chengdu 610207, China; 15882071673@163.com (H.S.); sugarchangyu@163.com (C.T.); \\ m18180544316@163.com (J.Y.); yongsli718@163.com (Y.L.); congwang_polymer@163.com (C.W.); \\ meijun12@126.com (J.M.) \\ 3 Science and Technology on Surface Physics and Chemistry Laboratory, Mianyang 621907, China; \\ shuaimb@sina.com \\ * Correspondence: hezhoukunhe@yinhe596.cn (Z.H.); lixiuyun@swust.edu.cn (X.L.); \\ Tel.: +86-822-440-7693 (Z.H.); +86-390-901-9537 (X.L.)
}

Received: 17 January 2018; Accepted: 19 March 2018; Published: 23 March 2018

\begin{abstract}
Poly(chloro-p-xylylene) (PPXC) film has a water contact angle (WCA) of only about $84^{\circ}$. It is necessary to improve its hydrophobicity to prevent liquid water droplets from corroding or electrically shorting metallic circuits of semiconductor devices, sensors, microelectronics, and so on. Herein, we reported a facile approach to improve its surface hydrophobicity by varying surface pattern structures under different temperature and relative humidity $(\mathrm{RH})$ conditions on a thermal curable polydimethylsiloxane (PDMS) and hydrophobic silica $\left(\mathrm{SiO}_{2}\right)$ nanoparticle coating. Three distinct large-scale surface patterns were obtained mainly depending on the contents of $\mathrm{SiO}_{2}$ nanoparticles. The regularity of patterns was mainly controlled by the temperature and $\mathrm{RH}$ conditions. By changing the pattern structures, the surface wettability of PPXC film could be improved and its WCA was increased from $84^{\circ}$ to $168^{\circ}$, displaying a superhydrophobic state. Meanwhile, it could be observed that water droplets on PPXC film with superhydrophobicity were transited from a "Wenzel" state to a "Cassie" state. The PPXC film with different surface patterns of $200 \mu \mathrm{m} \times 200 \mu \mathrm{m}$ and the improved surface hydrophobicity showed wide application potentials in self-cleaning, electronic engineering, micro-contact printing, cell biology, and tissue engineering.
\end{abstract}

Keywords: Poly(chloro-p-xylylene); surface wettability; polydimethylsiloxane; silica nanoparticles; superhydrophobic coating

\section{Introduction}

Poly(chloro-p-xylylene) (PPXC) film has been extensively applied in the fields of semiconductor devices, sensors, microelectronics, material moisture protection, and so on [1-4]. However, it has weak hydrophobicity with a water contact angle (WCA) of only about $84^{\circ}$ [5]. It is necessary to improve its hydrophobicity to prevent liquid water droplets from corroding or electrically shorting metallic circuits of the devices. Superhydrophobic coating [6-14] with a WCA greater than $150^{\circ}$ and a sliding 
angle (SA) of less than $10^{\circ}$ was used to prevent water droplets from wetting PPXC film. A facile strategy of improving surface hydrophobicity to superhydrophobicity of PPXC film is important in industrial applications of PPXC film [15-17]. The surface wettability can be tuned by changing surface morphologies or surface chemical compositions [18-26]. Regulation of surface morphologies had been extensively explored for pattern structures [27-34], which could be obtained by printing [35,36], self-assembly of block copolymer [37], and femtosecond laser structuring [38]. However, these methods could not satisfy the requirements of industrial applications due to some key defects, such as the small area of patterns, multi-step processes, and high cost.

Breath figures (BF) based on self-assembled water droplet arrays as dynamic templates had been extensively used to produce ordered honeycomb polymer films. This method had obvious advantages in cost and versatility [39-42], but the surface morphologies of BF films were closely related to the self-assembled water droplet arrays, which could be tuned by changing solvents, polymers, the concentration of solution, the temperature, and relative humidity (RH) [43,44]. Due to the complexity of these influencing factors, a facile and inexpensive strategy to obtain large-scale patterns on PPXC film still remains a challenge. Controlling the treatment conditions of polymer coating such as temperature and $\mathrm{RH}$ was considered as a facile strategy to achieve tunable surface morphology and wettability. However, the effects of temperature and RH on the anti-stick plastic substrates such as PPXC film were seldom reported. Besides, most of previous studies on the BF method were focused on polymers without thermal curing such as polystyrene, and thermal curable polymers such as polydimethylsiloxane (PDMS) used as replica materials were seldom explored $[45,46]$. Meanwhile, the introduction of hydrophobic silica $\left(\mathrm{SiO}_{2}\right)$ nanoparticles under temperature and $\mathrm{RH}$ treatments would have great effects on the surface morphology and surface wettability of PPXC film. Therefore, we herein reported a facile strategy to obtain large-scale patterns of $200 \mu \mathrm{m} \times 200 \mu \mathrm{m}$ and tune surface wettability of PPXC film with a thermal curable PDMS $/ \mathrm{SiO}_{2}$ coating. The pattern structures obtained by the BF method were usually porous honeycomb structures, but herein three structures (special raised bowl-shaped structures, traditional porous structures, and nanoparticle aggregation structures) were obtained on PPXC film. Moreover, the effects of different treatment conditions such as the content of $\mathrm{SiO}_{2}$ nanoparticles, thermal cross-linking temperature of PDMS, and $\mathrm{RH}$ on the morphology evolution of $\mathrm{PDMS} / \mathrm{SiO}_{2}$ coatings were explored systematically, and the surface wettability of PPXC film could be improved from weak hydrophobicity with a WCA of about $84^{\circ}$ to superhydrophobicity with a WCA of about $168^{\circ}$. Meanwhile, a typical transition of water droplets from a "Wenzel" state to a "Cassie" state on the surface was observed after tuning the treatment conditions. This transition was demonstrated by the sliding behavior of water droplets on the surface and the temporal changes of WCA on samples. To the best of our knowledge, it is the first time this engineering strategy to obtain large-scale different patterns on PPXC film, without destroying the original PPXC film, has been reported.

\section{Materials and Methods}

\subsection{Materials}

Poly(chloro-p-xylylene) (PPXC) film with a thickness of about $110 \mu \mathrm{m}$ was kindly provided by China Academy of Engineering Physics. Polydimethylsiloxane adhesive (PDMS, SE1700) and its curing agent (10:1 in weight ratio) were purchased from Dow Corning (Midland, MI, USA). Hydrophobic $\mathrm{SiO}_{2}$ nanoparticles (JT-SQ, 10 30 nm) were purchased from Chengdu Today Company (Chengdu, China). Alcohol and hexamethylene were issued by Kelong Chemical Company (Chengdu, China). Deionized water was produced by a water purifier purchased from Thermo Scientific (NANO pure, Waltham, MA, USA) to obtain a certain RH condition. 


\subsection{Dip Coating $\mathrm{PDMS} / \mathrm{SiO}_{2}$ on PPXC Film}

The PDMS with curing agent (10:1 in weight ratio) and $\mathrm{SiO}_{2}$ nanoparticles $(0.0 \sim 2.5 \mathrm{wt} \%$ in the whole suspension) were dispersed in hexamethylene under an ultrasonication (100 W) for $30 \mathrm{~min}$ to form a homogeneous suspension $(40 \mathrm{mg} / \mathrm{mL}$, Figure 1a). The PPXC film was firstly cleaned with alcohol and deionized water three times. After that, it was dip-coated one time in PDMS-based suspension for $5 \mathrm{~min}$ by a dip coating machine (SYDC-100, Shanghai SAN-YAN Technology Co., Ltd., Shanghai, China) at a lowering speed of $6000 \mu \mathrm{m} / \mathrm{s}$ and a lifting speed of $1000 \mu \mathrm{m} / \mathrm{s}$ (Figure 1b). Then, the coated PPXC film was treated at different temperatures $\left(60\right.$ or $\left.80{ }^{\circ} \mathrm{C}\right)$ and $\mathrm{RH}(55 \%$ or $95 \%)$ for $90 \mathrm{~min}$ in a constant-temperature and constant-humidity environmental test chamber (Figure 1c, LX/JS01, Shanghai Luxuan Apparatus, Shanghai, China). Finally, samples with different patterns were taken out of the chamber for further characterization after the evaporation of water droplets and the thermal curing of PDMS (Figure 1d).

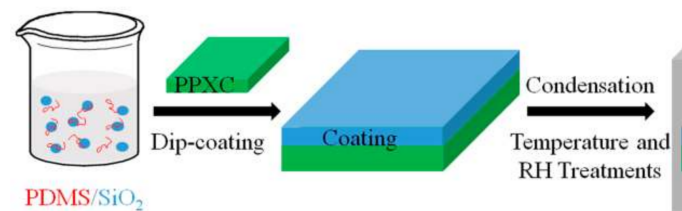

(a)

(b)

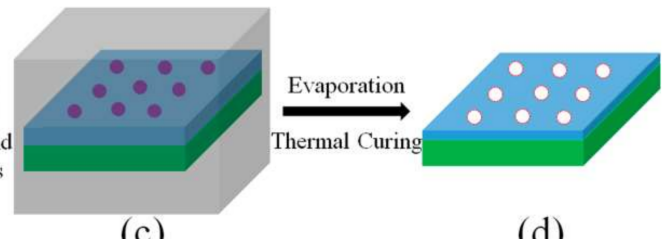

(c) (d)

Figure 1. Fabrication procedures of Polydimethylsiloxane (PDMS) $/ \mathrm{SiO}_{2}$ coating on Poly(chloro-pxylylene) (PPXC) film controlled by different temperatures and relative humidity (RH) treatment conditions. (a) Fabrication of $\mathrm{PDMS} / \mathrm{SiO}_{2}$ suspension; (b) Dip coating of $\mathrm{PDMS} / \mathrm{SiO}_{2}$ on $\mathrm{PPXC}$ film; (c) Water droplet condensation on PPXC film in controlled temperature and RH conditions; (d) Thermal curing of PDMS $/ \mathrm{SiO}_{2}$ coating on PPXC film and evaporation of water droplets.

\subsection{Characterization}

\subsubsection{Differential Scanning Calorimetry (DSC) Measurements}

A DSC instrument (Mettler Toledo, Zurich, Switzerland) was implemented to observe the thermal curing behavior of PDMS. For the non-isothermal curing measurement, the sample was heated from 30 to $200{ }^{\circ} \mathrm{C}$ at a heating rate of $10^{\circ} \mathrm{C} / \mathrm{min}$ in a nitrogen atmosphere. For the isothermal curing measurement, the sample in the DSC cell was quickly heated to the desired curing temperature and then maintained at that constant temperature for $90 \mathrm{~min}$. For each sample, three replicate scans at different positions were collected to confirm the final results.

\subsubsection{Fourier Transform Infrared (FTIR) Measurements}

The curing reaction of PDMS on PPXC film was explored by FTIR (Nicolet-iS10, Thermo Fisher Company, Waltham, MA, USA) in the range of $4000-400 \mathrm{~cm}^{-1}$ under a transmittance mode. The samples were mixed with $\mathrm{KBr}$ powder and then pressed into disks with a thickness of $0.3 \mathrm{~mm}$ for FTIR characterization. For each sample, three replicate scans at different positions were tested to confirm the shown value.

\subsubsection{Surface Morphology Observation}

The surface morphologies of samples were reviewed by scanning electron microscopy (SEM, XL-30-ESEM-FEG instrument, FEI PHILIPS, Brno, Czech Republic) under an acceleration voltage of $20 \mathrm{kV}$ at three different positions. A thin layer of Au was sputter-coated on the film to improve its conductivity before the test. Atomic force microscopy (AFM) images were produced by an atomic force microscope (SPI4000, Seiko Instruments, Chiba, Japan) at ambient conditions in a tapping mode. Commercial silicon nitride tips with the tip radius of about $10 \mathrm{~nm}$ were used as received from the indentors in the AFM indentation 
experiments. Meanwhile, the surface roughness (root-mean-square, RMS) of the samples was the average of five measurements of scan areas of $20 \mu \mathrm{m} \times 20 \mu \mathrm{m}$.

\subsubsection{Contact Angle Measurements}

The static water contact angles (WCA) of the samples were carried on a contact angle goniometer (DSA100, Kruss, Hamburg, Germany) with a volume of $5 \mu \mathrm{L}$ of deionized water droplets on the surface at ambient temperature. The dynamic water droplet behavior was characterized by a sliding angle (SA) of $10 \mu \mathrm{L}$ of deionized water droplets on the surface at ambient temperature. The WCA and SA mentioned in this study were the averaged value of at least five different positions on each sample.

\section{Results and Discussion}

\subsection{Effects of Temperature, $\mathrm{RH}$, and Content of $\mathrm{SiO}_{2}$ on the Curing Behavior of PDMS}

Owing to the thermal curability of PDMS, the temperature is an important factor in the cross-linking reaction process. As shown in Figure $2 \mathrm{a}$, the non-isothermal exothermic curve characterized by DSC indicates that the PDMS curing reaction occurs at about $60{ }^{\circ} \mathrm{C}$ and reaches a maximum reaction rate at near $120{ }^{\circ} \mathrm{C}$ with the appearance of an exothermic peak. To further investigate the cross-linking reaction behavior of PDMS at different temperatures, isothermal DSC curves of PDMS at 120, 80, 60, and $50{ }^{\circ} \mathrm{C}$ for $90 \mathrm{~min}$ were determined (Figure $2 \mathrm{~b}$ ). The curing reaction reaches a maximum rate within $40 \mathrm{~s}$ at $120^{\circ} \mathrm{C}$ with the appearance of an obvious exothermic peak, but only a small exothermic peak occurred within $60 \mathrm{~s}$ at 80,60 , or $50{ }^{\circ} \mathrm{C}$ (red rectangle frame in Figure $2 \mathrm{~b}$ and enlarged image in Figure 3a). Therefore, the curing reaction rate was obviously decreased at a lower curing temperature, and the required curing time of PDMS was increased. At $120^{\circ} \mathrm{C}$, the cross-linking reaction ends within $500 \mathrm{~s}$, but it extended to $3000 \mathrm{~s}$ at 80,60 , or $50{ }^{\circ} \mathrm{C}$ (red rectangle frame in Figure $2 \mathrm{~b}$, and enlarged image in Figure $3 b$ ). Therefore, the curing reaction time for all samples in this study was set as $90 \mathrm{~min}$ to ensure the complete curing of PDMS. Based on the elasticity of cured PDMS, we further investigated whether the PDMS was completely cured or not by a repeated stretching test of the sample after curing at 80,60 , and $50{ }^{\circ} \mathrm{C}$ for 90 min under $55 \% \mathrm{RH}$ (abbreviated as $80{ }^{\circ} \mathrm{C}-55 \% \mathrm{RH}$ ). The completely cured PDMS with good elasticity after curing at $80^{\circ} \mathrm{C}$ and $60^{\circ} \mathrm{C}$ could retain its original shape after several stretches (Figure 2c,d). However, the sample cured at $50{ }^{\circ} \mathrm{C}$ showed a typical viscous state (Figure 2e) indicating that PDMS was not completely cured. Therefore, the cross-linking reaction temperature of PDMS with a completely cured state for 90 min under 55\% RH should not be lower than $60^{\circ} \mathrm{C}$.

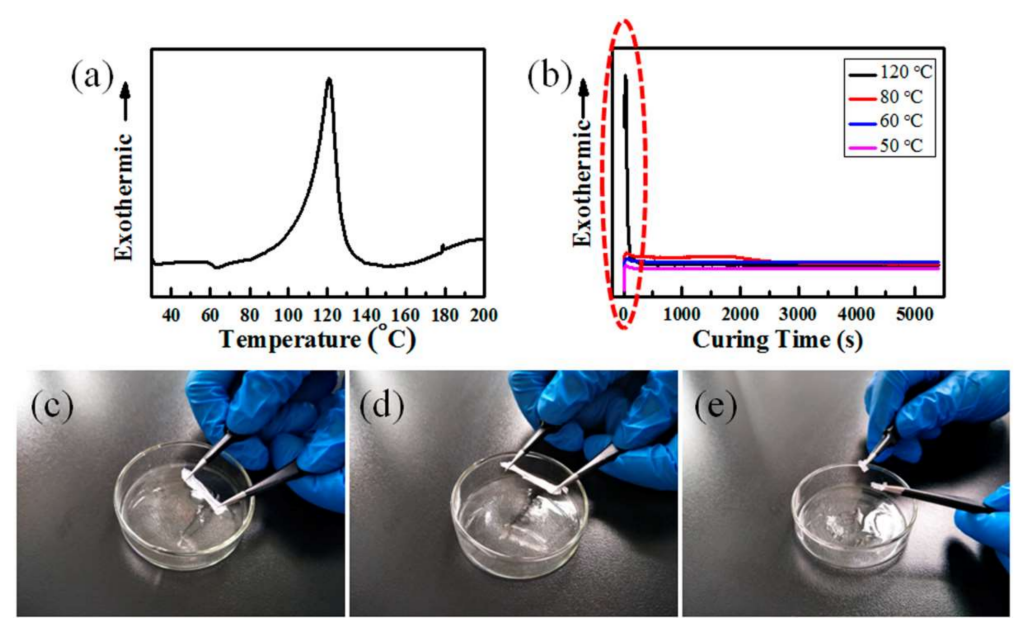

Figure 2. (a) Non-isothermal from 30 to $200{ }^{\circ} \mathrm{C}$; (b) Isothermal DSC curves for $90 \mathrm{~min}$ at different temperatures of PDMS; (c-e) Screenshots of PDMS during stretching after different curing temperatures at 80,60 , and $50{ }^{\circ} \mathrm{C}$ for 90 min under $55 \% \mathrm{RH}$. 

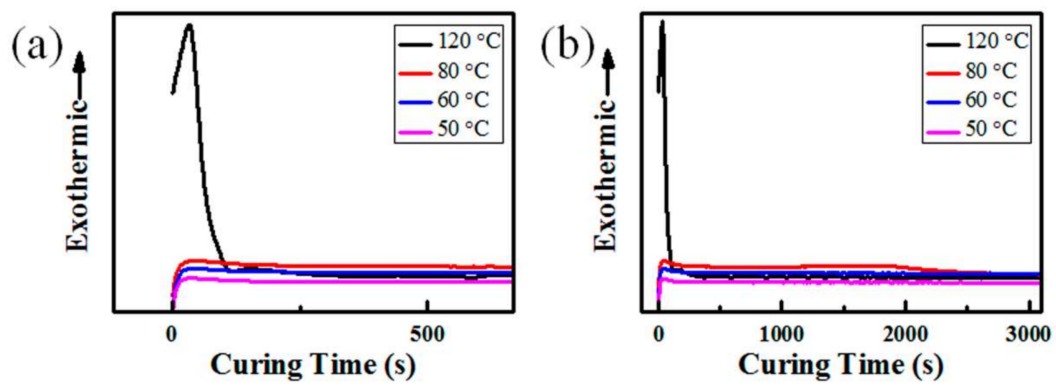

Figure 3. Enlarged images of isothermal differential scanning calorimetry (DSC) curves of PDMS treated at different temperatures. (a) Curing time within $500 \mathrm{~s}$; and (b) Curing time within $3000 \mathrm{~s}$.

Furthermore, FTIR results shown in Figure 4 are used to investigate the effects of higher RH (95\%) and different contents of $\mathrm{SiO}_{2}$ nanoparticles on the cross-linking reaction of PDMS. As for the sample ( $0.0 \mathrm{wt} \%$ of $\left.\mathrm{SiO}_{2}\right)$ without curing, the reactive groups of $\mathrm{Si}-\mathrm{H}\left(2162 \mathrm{~cm}^{-1}\right)$ and $\mathrm{C}=\mathrm{C}\left(1614 \mathrm{~cm}^{-1}\right)$ are obviously observed in green dash line. However, there are no typical peaks for these reactive groups after the cross-linking reaction at $60{ }^{\circ} \mathrm{C}-95 \% \mathrm{RH}$, indicating that PDMS can be thermally cured completely under a higher RH compared to a lower RH (55\%) shown in Figure 2d. Similarly, the reactive groups of $\mathrm{Si}-\mathrm{H}$ and $\mathrm{C}=\mathrm{C}$ also cannot be observed after curing at $60{ }^{\circ} \mathrm{C}-95 \% \mathrm{RH}$ for the samples with the increased contents of $\mathrm{SiO}_{2}$ nanoparticles (1.0 and $2.5 \mathrm{wt} \%$ of $\mathrm{SiO}_{2}$ ). Meanwhile, the characteristic peaks indicated the existence of typical groups in PDMS molecular chains at $2965 \mathrm{~cm}^{-1}, 1404 \mathrm{~cm}^{-1}$, $1082 \mathrm{~cm}^{-1}$, and $797 \mathrm{~cm}^{-1}$ ascribed to $-\mathrm{CH}_{3}$ and Si-O-Si groups, respectively. Thus, the higher $\mathrm{RH}$ and different contents of $\mathrm{SiO}_{2}$ nanoparticles had no obvious effect on the complete thermal curing of PDMS at $60{ }^{\circ} \mathrm{C}$ for $90 \mathrm{~min}$. Therefore, the surface morphologies of samples treated for $90 \mathrm{~min}$ in the study were in a stable and ultimate state and the surface morphology evolution is discussed below.

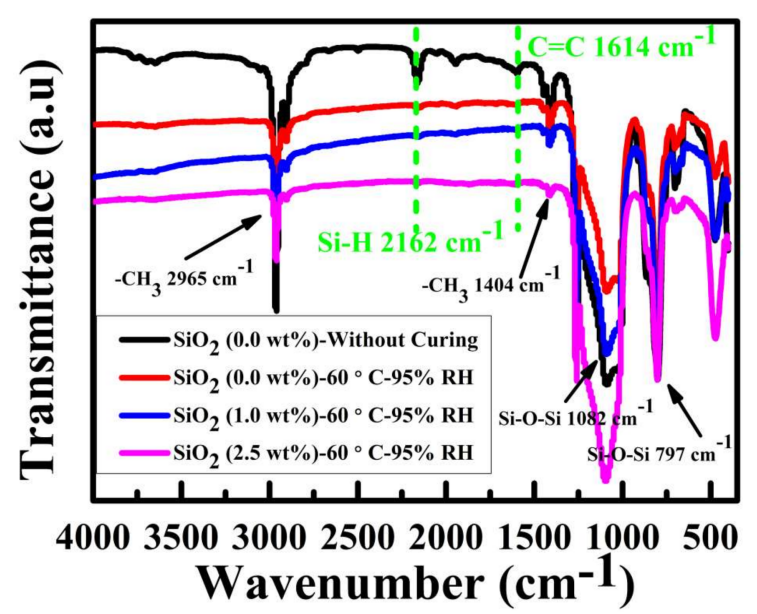

Figure 4. FTIR results of the samples with different contents of $\mathrm{SiO}_{2}$ at $60{ }^{\circ} \mathrm{C}-95 \% \mathrm{RH}$ treatment.

\subsection{Surface Morphology Evolutions of PDMS/SiO ${ }_{2}$ Coating on PPXC Film under Different Treatment Conditions}

Although PDMS with different contents of $\mathrm{SiO}_{2}$ (from 0.0 to $2.5 \mathrm{wt} \%$ ) could be thermally cured completely at different cross-linking reaction temperatures $\left(120,80\right.$, and $60{ }^{\circ} \mathrm{C}$ for $\left.90 \mathrm{~min}\right)$ and different $\mathrm{RH}$ treatment conditions ( $55 \%$ and $95 \%$ ), the cross-linking reaction processes might differ from each other and result in different surface morphologies. SEM and AFM images were implemented to confirm this prediction. Surface morphology evaluation of the samples with different contents of $\mathrm{SiO}_{2}$ $(0.0,0.5,1.0$, and $2.0 \mathrm{wt} \%)$ treated at $80{ }^{\circ} \mathrm{C}-55 \% \mathrm{RH}$ is shown in Figure 5. A large number of special raised bowl-shaped structures (RBS) could be found on the surface of PPXC film with pure PDMS. 
The special RBS showed the homogeneous distribution on the whole PPXC film (Figure 5(a-0.0)), but a similar phenomenon was not reported in previous studies on PPXC film with different temperatures or RH treatment conditions. Furthermore, a higher magnification of RBS is characterized by the AFM image (black circles in Figure 5(b-0.0). Most of the RBS had a similar typical dimension of about $7 \mu \mathrm{m}$ in length, and the periphery of RBS was obviously higher than the center of RBS, as indicated by the altitude scale on the right of the AFM image.

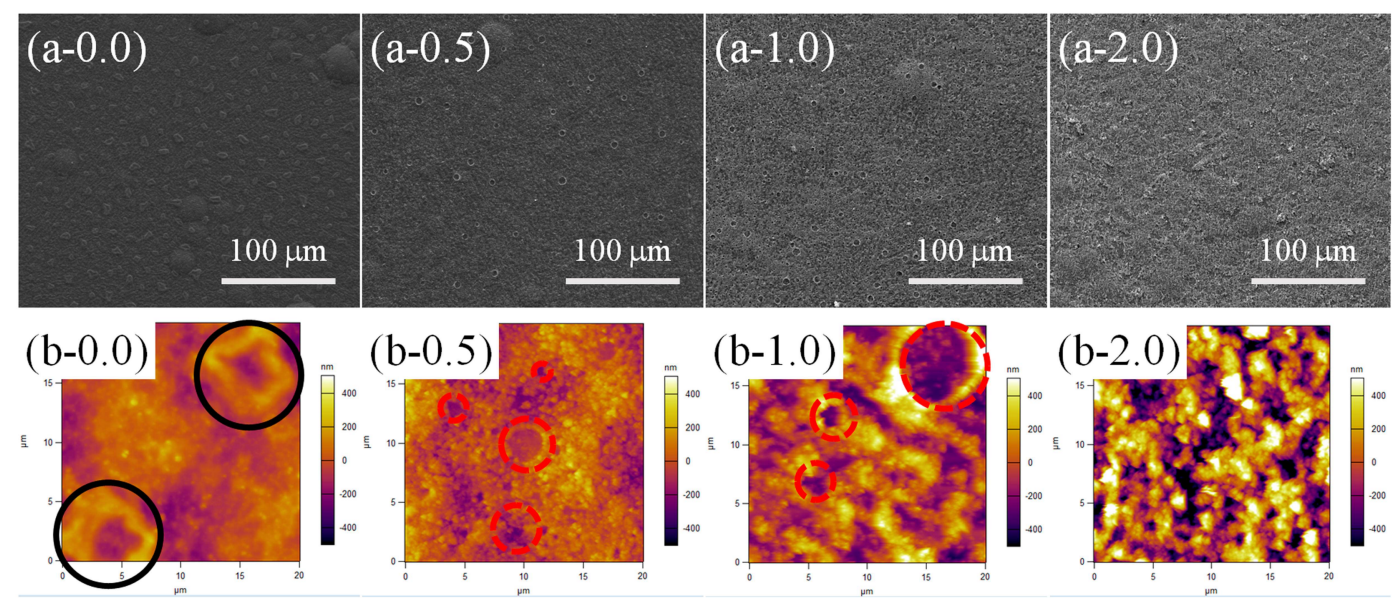

Figure 5. Scanning electron microscopy (SEM) (a-x) and higher magnification atomic force microscopy (AFM) (b-x) images for samples with different contents $(x)$ of $\mathrm{SiO}_{2}$ at $80{ }^{\circ} \mathrm{C}-55 \% \mathrm{RH}$ treatment.

When low contents ( 0.5 and $1.0 \mathrm{wt} \%$ ) of $\mathrm{SiO}_{2}$ nanoparticles were added in PDMS coating, RBS disappeared and the traditional porous structures (TPS, similar to the pores formed via a traditional "Breath Figures" method) appeared (Figure 5(a-0.5) and (a-1.0). The number of TPS showed no significant variation compared to that of RBS, but the dispersion of TPS is much larger than that of RBS (Figure 5(a-0.0)). Meanwhile, the dimension of TPS becomes inhomogeneous with a distribution between 1 and $7 \mu \mathrm{m}$ (red dash circles in high-magnification AFM images, Figure 5(b-0.5) and (b-1.0). With a high content (2.0 wt \%) of $\mathrm{SiO}_{2}$ nanoparticles in PDMS coating (Figure 5(a-2.0)), RBS or TPS did not appear, but a lot of nanoparticle aggregation structures (NAS) occurred, like previous studies $[47,48]$. The distribution of NAS is very homogeneous, as shown in a high-magnification AFM image (Figure 5(b-2.0)), due to the good dispersion of $\mathrm{PDMS}$ and $\mathrm{SiO}_{2}$ in hexamethylene solution.

As mentioned above, lower temperature increased the time required for the cross-linking reaction of PDMS. In this section, we further investigated the surface morphology evaluation of the samples with different contents of $\mathrm{SiO}_{2}(0.0,0.5,1.0$ and $2.0 \mathrm{wt} \%)$ at a lower curing temperature $\left(60{ }^{\circ} \mathrm{C}\right.$ for 90 min under 55\% RH, Figure 6). A large number of RBS with homogeneous distribution could be found on the whole PPXC film with pure PDMS (Figure 6(a-0.0)), showing a similar distribution to that in Figure 5(a-0.0). However, the number of RBS was much greater and the dimension of RBS became smaller with the length of only about $5 \mu \mathrm{m}$ after the treatment at $60{ }^{\circ} \mathrm{C}$ (Figure $6(\mathrm{~b}-0.0)$, black circles) compared to that obtained after the treatment at $80{ }^{\circ} \mathrm{C}$ (Figure $5(\mathrm{~b}-0.0)$ ). After the low content $(0.5$ and $1.0 \mathrm{wt} \%$ ) of $\mathrm{SiO}_{2}$ nanoparticles were added in PDMS coating, RBS disappeared, and TPS appeared (Figure 6(a-0.5) and (a-1.0)), showing the same morphology as that obtained after the treatment at $80{ }^{\circ} \mathrm{C}$ (Figure 5(a-0.5) and (a-1.0)).

The number of TPS increased, but the dispersion of TPS showed no significant change compared to that of RBS (Figure 6(a-0.0)). Meanwhile, the dimension of TPS became smaller with a homogeneous distribution close to $1 \mu \mathrm{m}$ (red dash circles in AFM images, Figure 6(b-0.5) and (b-1.0)) compared to that of RBS (Figure 6(b-0.0)). After high contents (2.0 wt \%) of $\mathrm{SiO}_{2}$ nanoparticles were added into PDMS coating (Figure 6(a-2.0) and (b-2.0)), lots of NAS with homogeneous distribution were found, similar to that in Figure 5(a-2.0) and (b-2.0). 
Moreover, the effect of a higher RH on the surface morphology evaluation of samples with different contents of $\mathrm{SiO}_{2}(0.0,0.5,1.0$ and $2.0 \mathrm{wt} \%)$ was also investigated at a lower temperature $\left(60{ }^{\circ} \mathrm{C}\right.$ for $90 \mathrm{~min}$ under $\left.95 \% \mathrm{RH}\right)$ (Figure 7). Compared with the samples in Figure 5(a-0.0) and Figure 6(a-0.0), a large number of RBS could be found on the entire surface of PPXC film with pure PDMS (Figure 7(a-0.0)). However, the number of RBS obviously decreased and the dimension of some RBS with a severely inhomogeneous distribution became as long as about $45 \mu \mathrm{m}$ (or near $100 \mu \mathrm{m})$ (black circles in Figure 7(a-0.0) and (b-0.0)). For the coating with the low content (0.5 and $1.0 \mathrm{wt} \%$ ) of $\mathrm{SiO}_{2}$ nanoparticles, RBS disappeared, and TPS occurred. The number of TPS shows little change (Figure 7(a-0.5) and (a-1.0)), showing the same morphology as the samples treated at 55\% RH (Figure 6(a-0.5) and (a-1.0)). However, the dispersion and dimension of TPS increased a little (red dash circles in AFM images, Figure 7(b-0.5) and (b-1.0)) due to the appearance of some large-scale TPS compared to that in Figure 6(b-0.5) and (b-1.0). After high contents (2.0 wt \%) of $\mathrm{SiO}_{2}$ nanoparticles were added in PDMS coating (Figure 7(a-2.0) and (b-2.0)), lots of NAS still could be found, but there were still a few TPS, shown as red dash circles in Figure 7(b-2.0) compared to the samples in Figure 5(b-2.0) and Figure 6(b-2.0). The TPS should be attributed to the higher RH adopted in the sample treatment at $60{ }^{\circ} \mathrm{C}-95 \% \mathrm{RH}$.

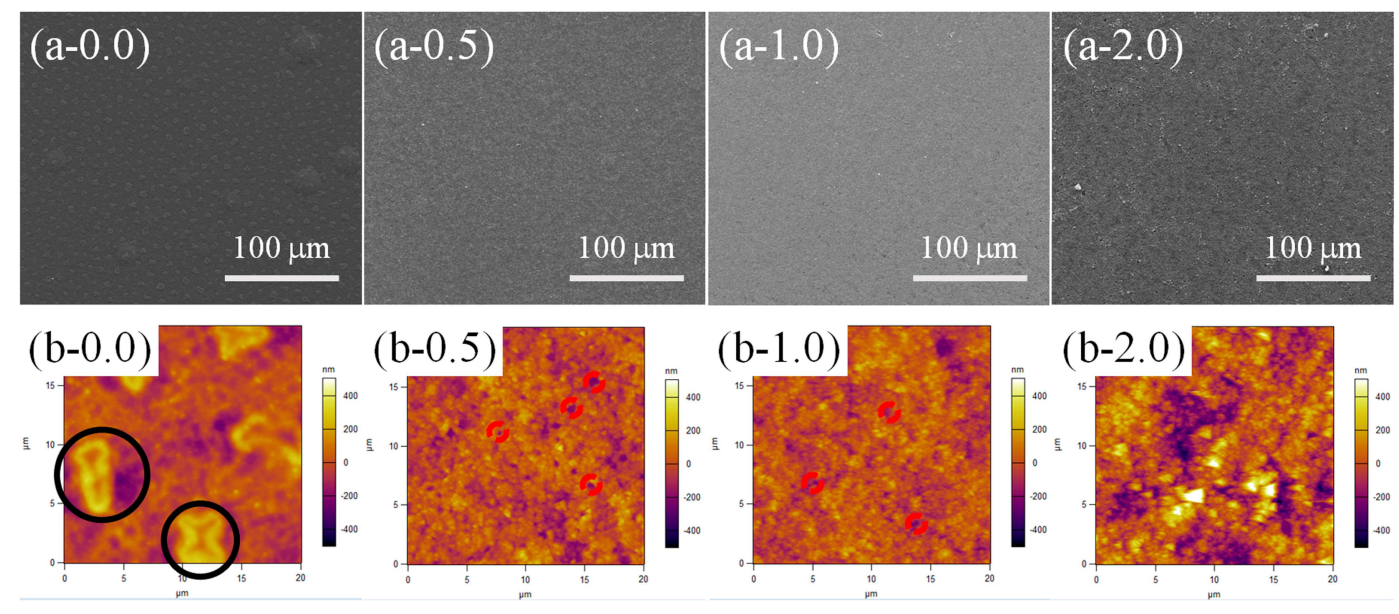

Figure 6. SEM (a-x) and higher magnification AFM (b-x) images for the samples with different contents $(x)$ of $\mathrm{SiO}_{2}$ at $60{ }^{\circ} \mathrm{C}-55 \% \mathrm{RH}$ treatment.
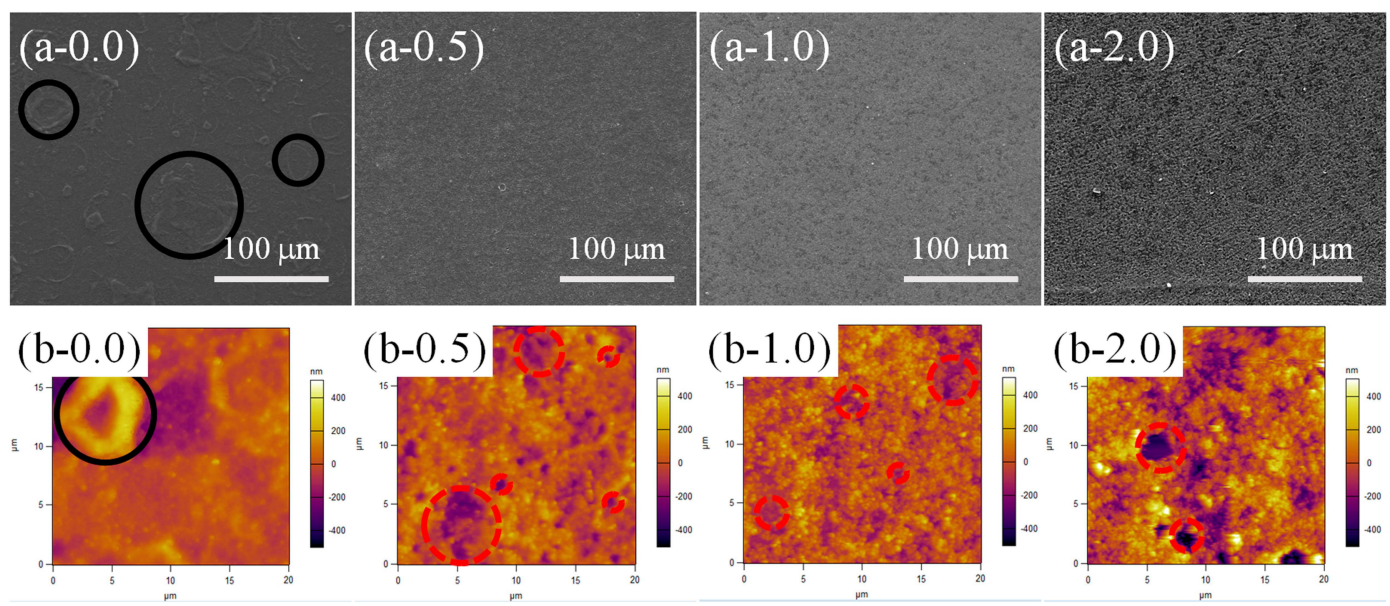

Figure 7. SEM (a-x) and high-magnification AFM (b-x) images for samples with different contents $(x)$ of $\mathrm{SiO}_{2}$ at $60^{\circ} \mathrm{C}-95 \% \mathrm{RH}$ treatment. 
To clearly reveal the mechanism of surface morphology evolution, the effects of cross-linking reaction temperature (upper row for $80^{\circ} \mathrm{C}$ and lower row for $60^{\circ} \mathrm{C}$ ), $\mathrm{RH}$ (left column for $55 \% \mathrm{RH}$ and right column for $95 \% \mathrm{RH}$ ), and content of $\mathrm{SiO}_{2}$ (left column for pure $\mathrm{PDMS}_{\text {without }} \mathrm{SiO}_{2}$, middle column for PDMS with a low content of $\mathrm{SiO}_{2}$, and right column for PDMS with a high content of $\mathrm{SiO}_{2}$ ) are shown in Figure 8. Based on the results in Figures 5-7, the conclusions can be drawn below.

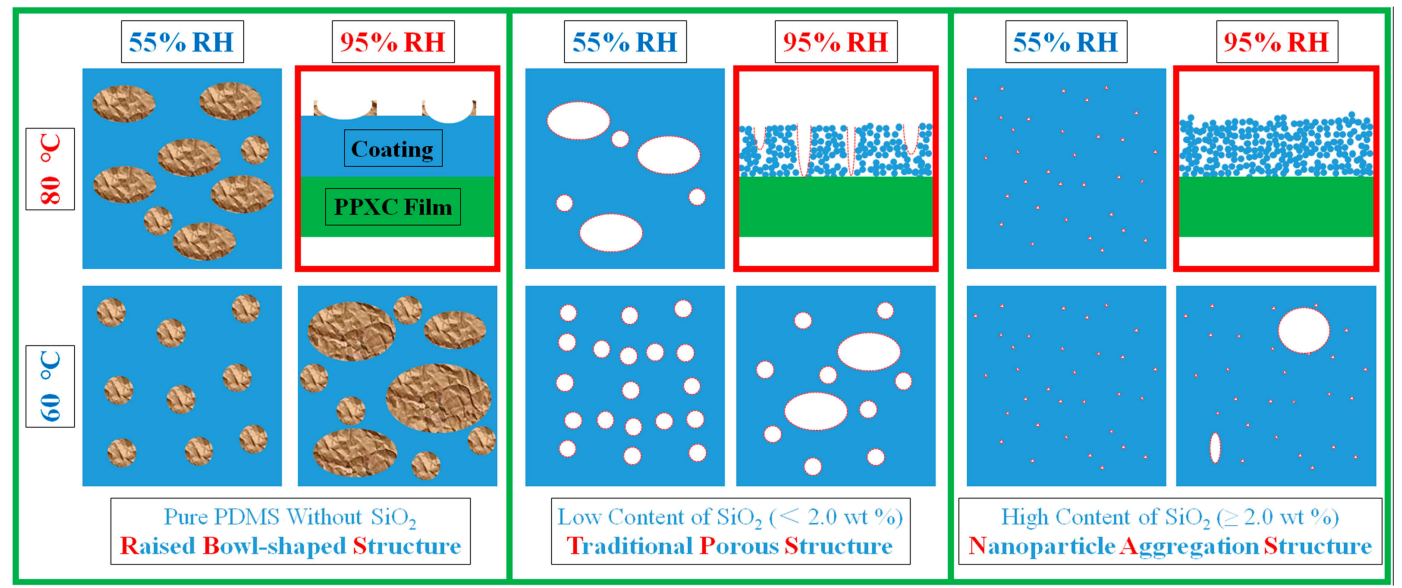

Figure 8. Morphology evolution scheme of the samples with different contents of $\mathrm{SiO}_{2}$, temperature and $\mathrm{RH}$ treatment conditions. Upper right schemes in red squares illustrate the cross-section morphologies of samples for raised bowl-shaped structures (RBS), traditional porous structures (TPS) and nanoparticle aggregation structures (NAS); schemes in upper left, lower left, and lower right illustrate the surface morphologies of samples with $80{ }^{\circ} \mathrm{C}-55 \% \mathrm{RH}$ treatment, $60{ }^{\circ} \mathrm{C}-55 \% \mathrm{RH}$ treatment, and $60{ }^{\circ} \mathrm{C}-95 \% \mathrm{RH}$ treatment, respectively.

Three different types of surface patterns (RBS, TPS, and NAS) with an area over $200 \mu \mathrm{m} \times 200 \mu \mathrm{m}$ were generated on PPXC film mainly by controlling the content of $\mathrm{SiO}_{2}$ nanoparticles. Firstly, as for the coating on PPXC film without $\mathrm{SiO}_{2}$ nanoparticles, only RBS could be found on the surface even at different cross-linking reaction temperatures and under different $\mathrm{RH}$ treatment conditions. It should be attributed to the repellence of PDMS molecular chains to condensed water droplets; the PDMS molecular chains migrated and finally cured at the three-phase contact line (the interface of coating phase, condensed water droplets phase, and air phase) to form typical RBS after the evaporation of condensed water droplets, as shown in the upper right image of the left column in Figure 8. Secondly, as for coatings with low contents of $\mathrm{SiO}_{2}$ nanoparticles (between zero and $2.0 \mathrm{wt}$ $\%$ ) shown in the middle column of Figure 8, RBS disappeared but TPS occurred under different cross-linking reaction temperatures and $\mathrm{RH}$ treatment conditions. The changed phenomenon might be interpreted as follows. The introduction of $\mathrm{SiO}_{2}$ nanoparticles greatly hindered the migration of PDMS molecular chains to the three-phase contact line. Nonetheless, PDMS molecular chains underneath condensed water droplets could still migrate to $\mathrm{SiO}_{2}$ nanoparticle aggregations due to the repellence to the sinking condensed water droplets. Therefore, many pores were formed with the evaporation of condensed water droplets, similarly with the formation process of pores via the traditional "Breath Figures" method. Thirdly, with the increase of $\mathrm{SiO}_{2}$ nanoparticles, TPS were gradually transformed into NAS and there were almost no TPS when the content increased to no less than $2.0 \mathrm{wt} \%$ (the right column in Figure 8). Condensed water droplets hardly sank into the large number of aggregated $\mathrm{SiO}_{2}$ nanoparticles due to the lower movability of nanoparticles than PDMS molecular chains. These three typical physical structures can be further demonstrated on sample treated by a high thermal cross-linking temperature $\left(80^{\circ} \mathrm{C}\right)$ and $\mathrm{RH}$ treatment condition $(95 \%)$ shown in Figure S1 in Supplementary Materials. There were still only RBS on the sample without $\mathrm{SiO}_{2}$ nanoparticles (Figure S1(a-0.0) and (b-0.0), black circles). TPS could be found with a low content of $\mathrm{SiO}_{2}$ nanoparticles (between zero and $2.0 \mathrm{wt} \%$, red dash circles) (Figure S1(a-0.5), (a-1.0) and (b-0.5), 
(b-1.0)). Meanwhile, TPS were gradually changed to NAS and there were almost no TPS when the content of $\mathrm{SiO}_{2}$ nanoparticles increased above $2.0 \mathrm{wt} \%$ (Figure S1(a-2.0) and (b-2.0)).

Under the same content of $\mathrm{SiO}_{2}$ nanoparticles, the number, distribution, and dimension of RBS showed similar variations with TPS and these variations could be tuned by changing thermal cross-linking temperature and RH treatment condition. At a higher temperature and under the same $\mathrm{RH}$ treatment conditions, the faster thermal curing of PDMS could not provide enough time for the formation of a stable RH condition to generate a large number of homogeneous condensed water droplets on the coating surface. Meanwhile, water vapor had more energy to show a more drastic Brownian Motion, which resulted in the formation of larger condensed water droplets with a decrease in the regularity. Therefore, the number was smaller and the distribution was less homogeneous. The dimension was larger for RBS and TPS at $80^{\circ} \mathrm{C}$ than that at $60^{\circ} \mathrm{C}$. Furthermore, compared to the lower RH condition (55\%), the higher RH condition (95\%) with more water vapor also resulted in the formation of larger condensed water droplets and a decrease in the number and regularity of RBS and TPS. We compared the samples (Figure S1) obtained with a higher thermal cross-linking temperature $\left(80^{\circ} \mathrm{C}\right)$ and higher $\mathrm{RH}$ treatment condition $(95 \%)$ with the samples (Figures $\left.5-7\right)$ obtained with a lower thermal cross-linking temperature $\left(60^{\circ} \mathrm{C}\right)$ and/or lower $\mathrm{RH}$ treatment condition $(55 \%)$ and found similar variations in RBS and TPS: the number of RBS or TPS became smaller; the distribution was less homogeneous, the dimension was increased.

Moreover, the number, distribution and dimension of TPS were affected by the content of $\mathrm{SiO}_{2}$ nanoparticles. The number decreased and the distribution became irregular. The dimension became smaller with the increase in the content of $\mathrm{SiO}_{2}$ nanoparticles (Figure 5(a-0.5)-(a-1.0), Figure 6(a-0.5)-(a-1.0), Figure 7(a-0.5)-(a-1.0) and Figure S1(a-0.5)-(a-1.0)). If the content of $\mathrm{SiO}_{2}$ nanoparticles reached $2.0 \mathrm{wt} \%$, TPS nearly disappeared and were transformed into NAS because the migration of PDMS molecular chains had been seriously hindered by the high content of $\mathrm{SiO}_{2}$ nanoparticles. Therefore, the thermal cross-linking temperature and $\mathrm{RH}$ treatment condition showed little effect on NAS, which seemed to be only controlled by the content of $\mathrm{SiO}_{2}$ nanoparticles (the right column in Figure 8).

\subsection{Surface Wettability of PDMS/SiO ${ }_{2}$ Coating on PPXC Film under Different Treatment Conditions}

According to previous studies, the surface wettability was usually determined by the rough physical structures and low surface energy chemical compositions. As the materials used in this study (both PDMS and hydrophobic $\mathrm{SiO}_{2}$ shown in Figure 4) were hydrophobic under different treatment conditions, the evolution of surface morphologies (Figures 5-7) should be responsible for the variations in surface wettability (Figure 9). RMS calculated from AFM images is shown in Figure 9a. The surface roughness increased monotonously and rapidly with the increase in the content of $\mathrm{SiO}_{2}$ nanoparticles for the samples treated at $80{ }^{\circ} \mathrm{C}$, but RMS showed a tiered growth for the samples treated at $60{ }^{\circ} \mathrm{C}$ (similar RMS of $85 \mathrm{~nm}$ for the samples with zero, 0.5 , and $1.0 \mathrm{wt} \% \mathrm{SiO}_{2}$; similar RMS of $110 \mathrm{~nm}$ for the samples with 1.5 and $2.0 \mathrm{wt} \% \mathrm{SiO}_{2}$; and similar RMS above $150 \mathrm{~nm}$ for the samples with 2.5 $\mathrm{wt} \% \mathrm{SiO}_{2}$ ). This special variation of RMS was ascribed to a faster thermal curing of PDMS at $80{ }^{\circ} \mathrm{C}$ than at $60^{\circ} \mathrm{C}$, so the surface physical structures were quickly immobilized without enough time to transform to homogeneous structures. The RMS variation of the samples treated at $60{ }^{\circ} \mathrm{C}-55 \% \mathrm{RH}$ and $60{ }^{\circ} \mathrm{C}-95 \% \mathrm{RH}$ indicated that RH had little effect on the statistic surface roughness but showed obvious effects on the number, distribution, and dimension of surface structures (Figures 5-8 and Figure S1). Due to the increase in RMS, WCA also increased gradually with the increase in the content of $\mathrm{SiO}_{2}$ nanoparticles (Figure 9b-d). As for the samples with RBS (pure PDMS without $\mathrm{SiO}_{2}$ ), WCA (Figure $9 \mathrm{~b}, \mathrm{c}$ ) was about $118^{\circ}$ and showed little increase compared to that on smooth PDMS [48] due to the increased roughness caused by RBS patterns (Figure 5 or Figure 6). Furthermore, WCA in Figure $9 \mathrm{~d}$ was only about $108^{\circ}$ for the sample treated at $60^{\circ} \mathrm{C}-95 \% \mathrm{RH}$ due to the much smoother RBS with a lower RMS (Figure 7, about $65 \mathrm{~nm}$ ) compared to that on the samples treated at $80{ }^{\circ} \mathrm{C}-55 \% \mathrm{RH}$ and $60{ }^{\circ} \mathrm{C}-55 \% \mathrm{RH}$ (Figures 5 and 6, about $89 \mathrm{~nm}$ ). Water droplets could not slide off all the samples 
with RBS even after $180^{\circ}$ reversal of the samples (the upper left profiles in Figure $9 \mathrm{~b}-\mathrm{d}$ ), indicating that water droplets on the surface were at a typical "Wenzel" state [49]. This should result from a lack of enough nano-scale roughness and the existence of only some micro-scale RBS (black circles in Figure 10, Figures S2 and S3) on the surface. Moreover, water droplets on the samples with TPS also could not slide off the surface (the left of red dash circles in Figure $9 b-d)$. As shown in the surface morphologies of the samples treated at $60{ }^{\circ} \mathrm{C}-55 \%$ RH in Figure 10(a-0.5), (b-0.5), (a-1.0), and (b-1.0) and the samples treated at $80{ }^{\circ} \mathrm{C}-55 \% \mathrm{RH}$ and $60{ }^{\circ} \mathrm{C}-95 \% \mathrm{RH}$ in Figures S2 and S3, micro-scale TPS (red dash circles) and nano-scale roughness based on $\mathrm{SiO}_{2}$ nanoparticle aggregations were increased, thus improving the surface hydrophobicity. However, water droplets were pinned on these samples with a WCA lower than $150^{\circ}$ for two reasons. Firstly, the low nano-scale roughness was caused by the too-low content of $\mathrm{SiO}_{2}$ nanoparticles (0.5 or $1.0 \mathrm{wt} \%$ ) and the submersion of some $\mathrm{SiO}_{2}$ nanoparticles into PDMS (white circles in Figure 10, Figure S2 and Figure S3). Secondly, the capillary effect of the pores from TPS and the gaps formed between $\mathrm{SiO}_{2}$ nanoparticle aggregations shown in red dash circles in Figure 10, Figure S2, and Figure S3 led to the phenomenon of water droplets.
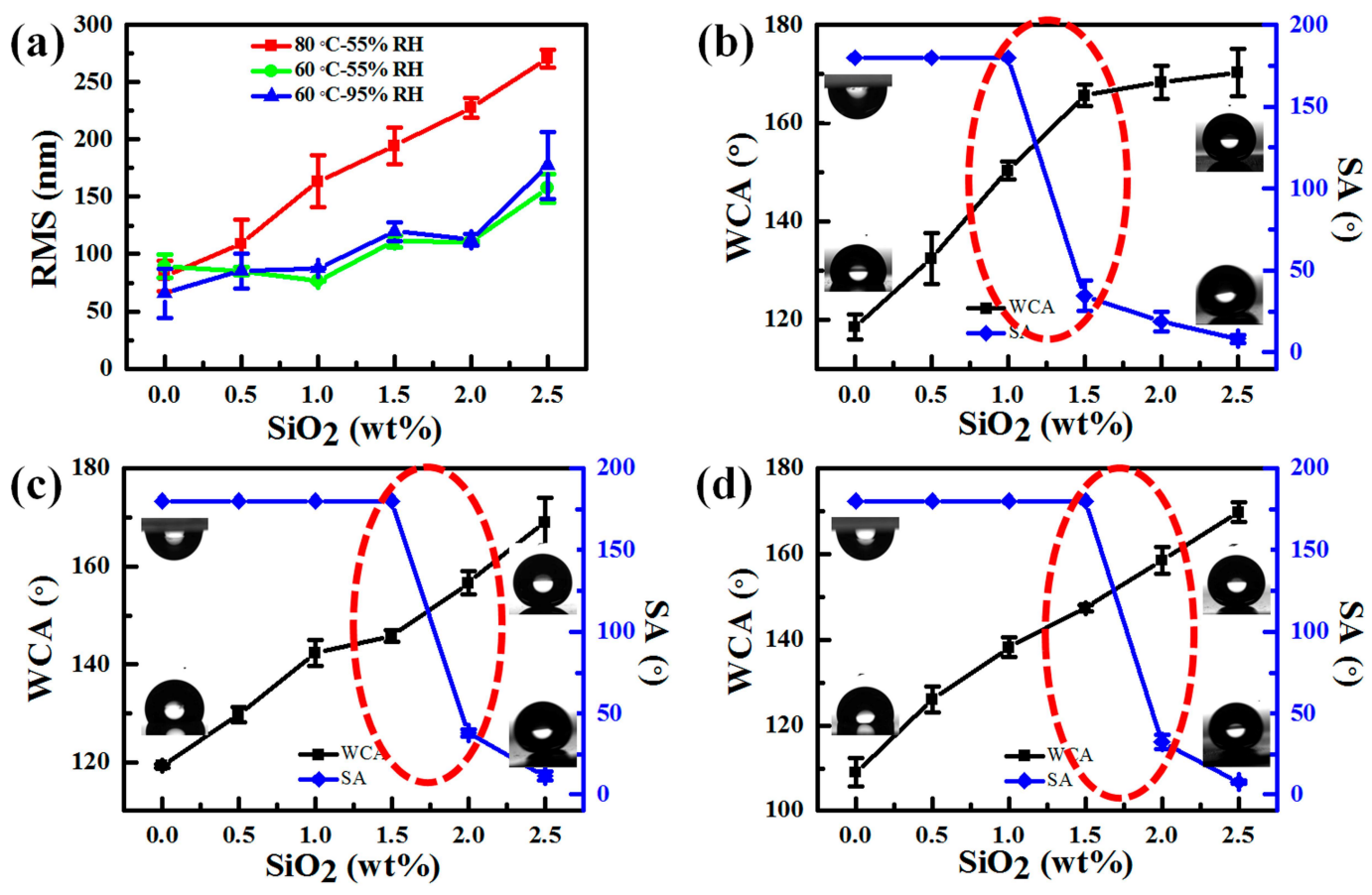

Figure 9. (a) Statistic surface roughness (RMS) on the samples with different contents of $\mathrm{SiO}_{2}$ under different $\mathrm{RH}$ treatment conditions $\left(80{ }^{\circ} \mathrm{C}-55 \% \mathrm{RH}\right.$ treatment (red square), at $60{ }^{\circ} \mathrm{C}-55 \% \mathrm{RH}$ treatment (green circle), and at $60^{\circ} \mathrm{C}-95 \% \mathrm{RH}$ treatment (blue triangular)); WCA and SA on the samples with different contents of $\mathrm{SiO}_{2}$ under different $\mathrm{RH}$ treatment conditions $\left(80{ }^{\circ} \mathrm{C}-55 \% \mathrm{RH}\right.$ treatment (b); $60{ }^{\circ} \mathrm{C}-55 \% \mathrm{RH}$ treatment (c); at $60{ }^{\circ} \mathrm{C}-95 \% \mathrm{RH}$ treatment (d)). Profiles in the lower left and upper right in Figure $9 b-d$ show the behaviors of static water droplets on the surface. Profiles in the upper left indicate that the water droplets cannot slide off the surface even after $180^{\circ}$ reversal of the surface, but profiles in the lower right indicate that the water droplets easily slide off the surface within $10^{\circ} \mathrm{SA}$. Water droplets still cannot slide off the surface with a "Wenzel" state shown in the red dash circles. 


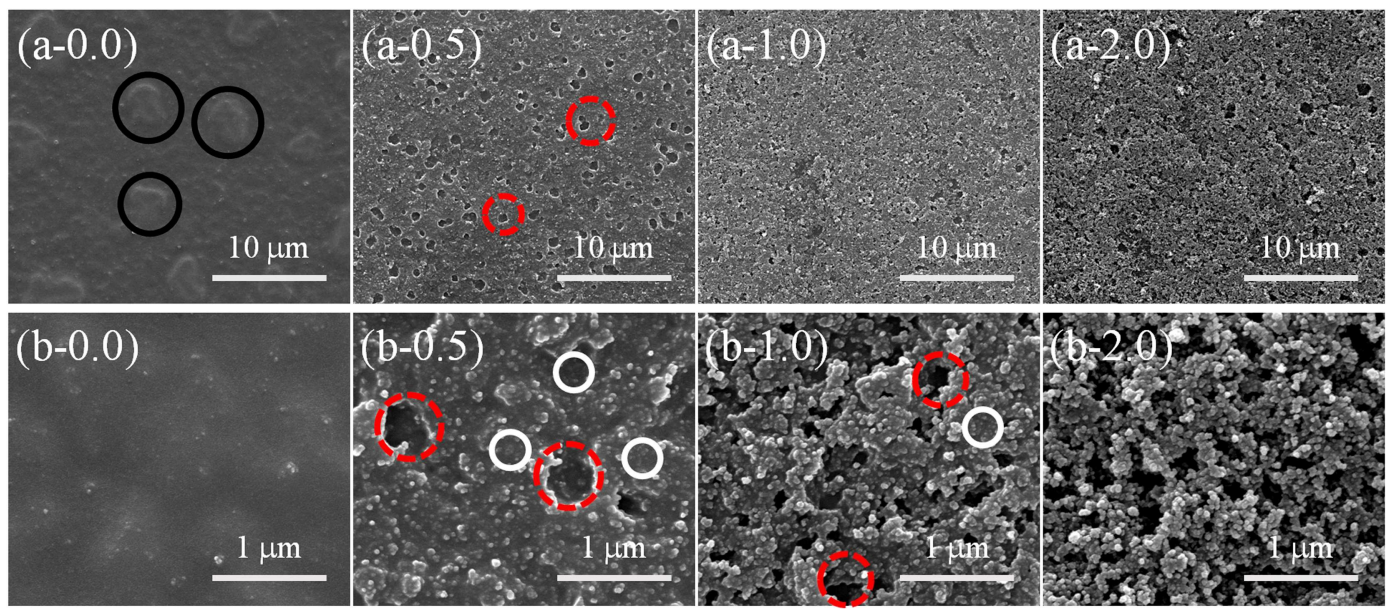

Figure 10. Surface micro-scale (SEM, a- $x$ ) and nano-scale (SEM, b-x) morphologies of the samples with different contents $(x)$ of $\mathrm{SiO}_{2}$ at $60{ }^{\circ} \mathrm{C}-55 \% \mathrm{RH}$.

When WCA on the samples was higher than $150^{\circ}$ (the right of red dash circles in Figure $9 \mathrm{~b}-\mathrm{d}$ ), water droplets began to slide off the surface with an SA less than $40^{\circ}$, showing a transition of water droplets from a "Wenzel" state to a "Cassie" state [49-51]. Samples in the left area of the circles were in a "Wenzel" state because water droplets could not slide off the surface even after $180^{\circ}$ reversal of the surface, and samples in the right area of the circles were in a "Cassie" state because water droplets began to slide off the surface with the help of the release of air bubbles underneath the droplets. This transition is consistent with the increase of surface RMS (Figure 9a). The samples treated at $60{ }^{\circ} \mathrm{C}-55 \% \mathrm{RH}$ and $60{ }^{\circ} \mathrm{C}-95 \% \mathrm{RH}$ showed a typical tiered growth of RMS and a sharp increase under $1.5 \mathrm{wt} \%$ of $\mathrm{SiO}_{2}$ nanoparticles, displaying a WCA close to $150^{\circ}$. The transition started under the conditions of $1.5 \mathrm{wt} \%$ of $\mathrm{SiO}_{2}$ nanoparticles and a WCA close to $150^{\circ}$. The special tiered growth of RMS should be interpreted as follows. Curing time required at $60^{\circ} \mathrm{C}$ was longer than that $80^{\circ} \mathrm{C}$ so that the migration of PDMS could achieve the more homogeneous morphologies. When the content of $\mathrm{SiO}_{2}$ nanoparticles reached $2.5 \mathrm{wt} \%$, in the sample treated at $80{ }^{\circ} \mathrm{C}-55 \% \mathrm{RH}$, RMS continued to increase to about $270 \mathrm{~nm}$; in the samples treated at $60{ }^{\circ} \mathrm{C}-55 \% \mathrm{RH}$ and $60{ }^{\circ} \mathrm{C}-95 \% \mathrm{RH}$ (Figure 9a), RMS sharply increased, thus resulting in a further increase of WCA and water droplets easily rolling off the surface with an SA of only about $8^{\circ}$. All the samples showed a typical "Cassie" state (Figure 9b-d). The changes should be ascribed to the special NAS similar to the sample containing $2.0 \mathrm{wt} \%$ of $\mathrm{SiO}_{2}$ nanoparticles (Figure 10(a-2.0) and (b-2.0)) and our previous studies.

Moreover, the precise transitions of water droplets from a "Wenzel" state to a "Cassie" state for samples treated at different conditions are shown in red dash circles in Figure 9b-d. Meanwhile, the profiles of water droplets for WCA and SA on different samples after being left in room conditions for about 6 months were shown in Figure 11. All the WCAs were close to $150^{\circ}$ and water droplets could not slide off the surfaces even after $180^{\circ}$ reversal of the samples if the samples were in a "Wenzel" state shown in the left columns of Figure 11a-c. However, water droplets began to slide off the surfaces due to the repellency of air bubbles underneath the water droplets if the samples were in a "Cassie" state, as shown in the right columns of Figure 11a-c. WCAs and the sliding behavior of water droplets on these samples showed little change compared with the as-prepared samples in Figure 9. Therefore, these samples showed a stable hydrophobicity or superhydrophobicity. This stability should be attributed to the complete cross-linking of PDMS after thermal treatment as demonstrated in Figures 2-4. Thus, these structures, RBS, TPS, and NAS, were achieved with one-step treatment within $90 \mathrm{~min}$. 


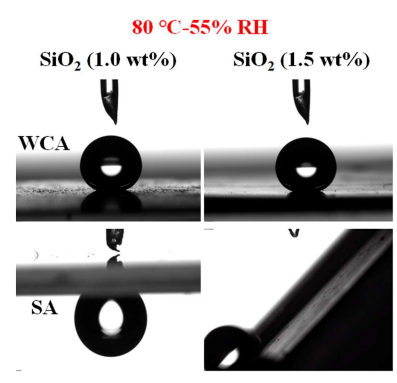

(a)

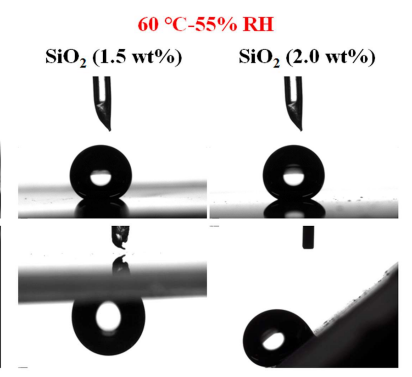

(b)

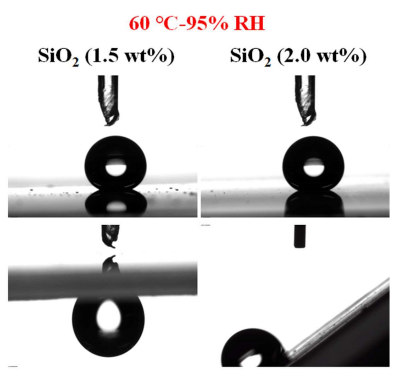

(c)

Figure 11. Profiles of water droplets for WCA (upper row) and SA (lower row) on different samples after being left in room conditions for about 6 months with different contents (left and right columns) of $\mathrm{SiO}_{2}$ at $80{ }^{\circ} \mathrm{C}-55 \% \mathrm{RH}(\mathbf{a}) ; 60{ }^{\circ} \mathrm{C}-55 \% \mathrm{RH}(\mathbf{b})$; and $60{ }^{\circ} \mathrm{C}-95 \% \mathrm{RH}(\mathbf{c})$.

The temporal changes of WCA on hydrophobic or superhydrophobic surfaces usually show only a little change, for example, less than $10^{\circ}$ decrease in $25 \mathrm{~h}$ for samples in the reference [19], and less than $5^{\circ}$ change in 30 days for superhydrophobic samples in previous publications [47]. In consideration of different kinds of structures in this manuscript, the temporal changes of WCA on samples with RBS, TPS, and NAS are shown in Figure 12. However, WCAs on RBS $\left(0.0 \mathrm{wt} \% \mathrm{SiO}_{2}\right)$ in Figure $12 \mathrm{a}, \mathrm{b}$ decreased about $17^{\circ}$ with $20 \mathrm{~min}$. This obvious decrease should be attributed to the firm adhesion of water droplets on RBS, and the three-phase contact line showed almost little change during the evaporation of water droplets. As for WCA on RBS $\left(1.5 \mathrm{wt} \% \mathrm{SiO}_{2}\right)$ in Figure $12 \mathrm{a}, \mathrm{c}$, it showed only about $5^{\circ}$ change, which should result from the shorter length of the three-phase contact line with a higher initial WCA. Meanwhile, the WCAs within $20 \mathrm{~min}$ for samples with lower contents of $\mathrm{SiO}_{2}$ (less than $2.0 \mathrm{wt} \%$ ) showed a steady decrease, which should be due to the samples in a "Wenzel" state and the firm adhesion of water droplets on RBS and TPS. When the contents of $\mathrm{SiO}_{2}$ increased to $2.0 \mathrm{wt} \%$ and $2.5 \mathrm{wt} \%$, WCA showed wavy change, which should be due to the samples in a "Cassie" state. With a "Cassie" state, air bubbles underneath the water droplets would escape from the edge of the three-phase contact lines during the evaporation of water droplets. The release of air bubbles would shorten the length of the three-phase contact line (blue dash lines in Figure 12d) and result in an increased WCA shown as red dash upward arrows (2.0 wt \%) and red downward arrows $(2.5 \mathrm{wt} \%)$ in Figure 12a.
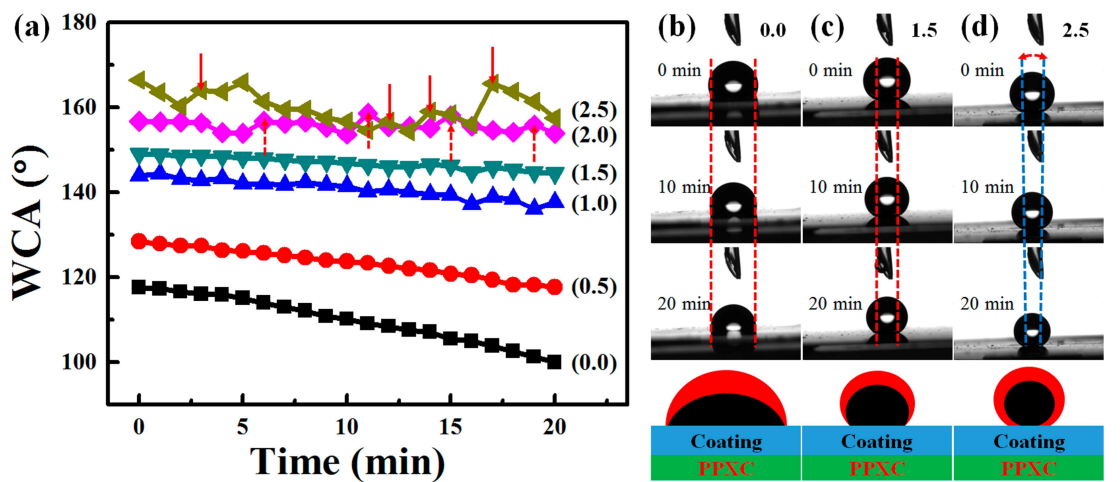

Figure 12. The evolution of WCA with time after deposition of the water droplets on samples with different contents of $\mathrm{SiO}_{2}$ at $60{ }^{\circ} \mathrm{C}-55 \% \mathrm{RH}(\mathbf{a})$; the profiles of water droplets on sample with 0.0 wt \% (b); $1.5 \mathrm{wt} \%$ (c); and $2.5 \mathrm{wt} \% \mathrm{SiO}_{2}$ (d); with $0 \mathrm{~min}, 10 \mathrm{~min}$, and $20 \mathrm{~min}$. The schemes in Figure $12 \mathrm{~b}-\mathrm{d}$ show the evolution of water droplets before (red) and after (black) evaporation. The red and blue dash lines in Figure 12b-d showed the edges of the three-phase contact lines during the evaporation of water droplets. The gradually decreased length of the three-phase contact line in Figure 12d was illustrated by the red dash arc double arrows and the scheme. 


\section{Conclusions}

In summary, PDMS could be well thermally cured at a temperature of $60{ }^{\circ} \mathrm{C}$ or higher for $90 \mathrm{~min}$. Meanwhile, the content of $\mathrm{SiO}_{2}$ nanoparticles and the relative humidity (55\% and 95\%) showed little effect on the complete curing of PDMS at $60{ }^{\circ} \mathrm{C}$ or higher temperature. However, among the samples treated at different temperatures and $\mathrm{RH}$ conditions, the cross-linking reaction process was different and resulted in different surface morphologies. By changing the contents of $\mathrm{SiO}_{2}$ nanoparticles, thermal cross-linking temperatures, or RH treatment conditions, three different types of large-scale surface patterns (RBS, TPS, and NAS) were obtained on PPXC film. Meanwhile, the number, distribution, and dimension of these three pattern structures were tuned by changing the experimental conditions. With the evolution of surface patterns, the surface wettability was changed from weak hydrophobicity to superhydrophobicity and the WCA increased from $84^{\circ}$ to $168^{\circ}$. A typical transition of water droplets from a "Wenzel" state to a "Cassie" state on the surface was observed. The PPXC film with different surface patterns of $200 \mu \mathrm{m} \times 200 \mu \mathrm{m}$ and the improved surface hydrophobicity showed wide application potentials in self-cleaning, electronic engineering, micro-contact printing, cell biology, tissue engineering, and so on.

Supplementary Materials: The following are available online at http:/ /www.mdpi.com/1996-1944/11/4/486/s1, Figure S1: SEM (a- $x)$ and high-magnification SEM (b- $x$ ) images for the samples with different contents $(x)$ of $\mathrm{SiO}_{2}$ at $80{ }^{\circ} \mathrm{C}-95 \% \mathrm{RH}$ treatment, Figure S2: Surface micro-scale (SEM, a- $x$ ) and nano-scale (SEM, b- $x$ ) morphologies of the samples with different contents $(x)$ of $\mathrm{SiO}_{2}$ at $80{ }^{\circ} \mathrm{C}-55 \% \mathrm{RH}$, Figure S3: Surface micro-scale (SEM, a- $x$ ) and nano-scale (SEM, b- $x$ ) morphologies of the samples with different contents $(x)$ of $\mathrm{SiO}_{2}$ at $60{ }^{\circ} \mathrm{C}-95 \% \mathrm{RH}$.

Acknowledgments: The authors would like to acknowledge the financial support from the National Natural Science Foundation of China (21504106 and 51573217), the program on rubber sealant with high barrier properties, and the Open Project of State Key Laboratory Cultivation Base for Nonmetal Composites and Functional Materials (11zxfk26).

Author Contributions: Yonglian Yu, Zhoukun He, and Xiuyun Li conceived and designed the experiment; Yonglian Yu and Zhoukun He performed the experiment; Hong Shao, Changyu Tang, Jian Yang, Yongsheng Li, Cong Wang, Maobing Shuai, and Jun Mei contributed reagents, material, analysis tools; and Yonglian Yu wrote the paper.

Conflicts of Interest: The authors declare no conflict of interest.

\section{References}

1. Galeotti, F.; Hartmann, L.; Botta, C. Robust surface patterning by parylene-reinforced breath figures: An enabling tool for liquid crystal microcell arrays. J. Coll. Interface Sci. 2016, 465, 47-53. [CrossRef] [PubMed]

2. Cortés-Salazar, F.; Deng, H.; Peljo, P.; Pereira, C.M.; Kontturi, K.; Girault, H.H. Parylene C coated microelectrodes for scanning electrochemical microscopy. Electrochim. Acta. 2013, 110, 22-29. [CrossRef]

3. Davis, E.M.; Benetatos, N.M.; Regnault, W.F.; Winey, K.I.; Elabd, Y.A. The influence of thermal history on structure and water transport in Parylene C coatings. Polymer 2011, 52, 5378-5386. [CrossRef]

4. Golda, M.; Brzychczy-Wloch, M.; Faryna, M.; Engvall, K.; Kotarba, A. Oxygen plasma functionalization of parylene C coating for implants surface: Nanotopography and active sites for drug anchoring. Mater. Sci. Eng. C Mater. Biol. Appl. 2013, 33, 4221-4227. [CrossRef] [PubMed]

5. Shao, H.; He, Z.; Xu, K.; Hu, X.; Zhou, Y.; Tang, C.; Mei, J.; Shuai, M.; Lau, W.-M.; Hui, D. Preparation of stable wetting surface by hyperthermal hydrogen induced cross-linking of poly(acrylic acid) on poly(chloro-p-xylylene) film. J. Phys. Chem. C 2016, 120, 28598-28606. [CrossRef]

6. Gupta, S.; He, W.-D.; Tai, N.-H. A comparative study on superhydrophobic sponges and their application as fluid channel for continuous separation of oils and organic solvents from water. Compos. Part. B Eng. 2016, 101, 99-106. [CrossRef]

7. Tan, H.; Diddens, C.; Versluis, M.; Butt, H.-J.; Lohse, D.; Zhang, X. Self-wrapping of an ouzo drop induced by evaporation on a superamphiphobic surface. Soft Matter 2017, 13, 2749-2759. [CrossRef] [PubMed]

8. Xiao, Y.; Huang, W.; Tsui, C.P.; Wang, G.; Tang, C.Y.; Zhong, L. Ultrasonic atomization based fabrication of bio-inspired micro-nano-binary particles for superhydrophobic composite coatings with lotus/petal effect. Compos. Part. B Eng. 2017, 121, 92-98. [CrossRef] 
9. Nouri, N.M.; Saadat-Bakhsh, M. Fabrication method of large-scale and mechanically durable superhydrophobic silicon rubber/aerogel coating on fibrous substrates. J. Coat. Technol. Res. 2017, 14, 477-488. [CrossRef]

10. Zang, D.; Zhu, R.; Zhang, W.; Yu, X.; Lin, L.; Guo, X.; Liu, M.; Jiang, L. Corrosion-resistant superhydrophobic coatings on mg alloy surfaces inspired by lotus seedpod. Adv. Funct. Mater. 2017, 27, 1605446. [CrossRef]

11. Zhang, D.; Qian, H.; Wang, L.; Li, X. Comparison of barrier properties for a superhydrophobic epoxy coating under different simulated corrosion environments. Corros. Sci. 2016, 103, 230-241. [CrossRef]

12. Zhu, M.; Tang, W.; Huang, L.; Zhang, D.; Du, C.; Yu, G.; Chen, M.; Chowwanonthapunya, T. Preparation of superhydrophobic film on ti substrate and its anticorrosion property. Materials 2017, 10, 628. [CrossRef] [PubMed]

13. Deng, X.; Mammen, L.; Zhao, Y.; Lellig, P.; Müllen, K.; Li, C.; Butt, H.-J.; Vollmer, D. Transparent, Thermally stable and mechanically robust superhydrophobic surfaces made from porous silica capsules. Adv. Mater. 2011, 23, 2962-2965. [CrossRef] [PubMed]

14. Ge, B.; Zhang, Z.; Men, X.; Zhu, X.; Zhou, X. Sprayed superamphiphobic coatings on copper substrate with enhanced corrosive resistance. Appl. Surf. Sci. 2014, 293, 271-274. [CrossRef]

15. Martin, S.; Brown, P.S.; Bhushan, B. Fabrication techniques for bioinspired, mechanically-durable, superliquiphobic surfaces for water, oil, and surfactant repellency. Adv. Colloid Interface 2017, 241, 1-23. [CrossRef] [PubMed]

16. Wang, Y.; Bhushan, B. Wear-resistant and antismudge superoleophobic coating on polyethylene terephthalate substrate using sio $_{2}$ nanoparticles. ACS Appl. Mater. Interfaces 2015, 7, 743-755. [CrossRef] [PubMed]

17. Deng, X.; Mammen, L.; Butt, H.J.; Vollmer, D. Candle soot as a template for a transparent robust superamphiphobic coating. Science 2012, 335, 67-70. [CrossRef] [PubMed]

18. Brown, P.S.; Bhushan, B. Mechanically durable, superoleophobic coatings prepared by layer-by-layer technique for anti-smudge and oil-water separation. Sci. Rep. 2015, 5, 8701. [CrossRef] [PubMed]

19. Boinovich, L.; Emelyanenko, A.; Pashinin, A.; Gnedenkov, S.; Egorkin, V.; Sinebryukhov, S. Mg alloy treatment for superhydrophobic anticorrosion coating formation. Surf. Innov. 2013, 1, 162-172. [CrossRef]

20. Qi, Y.; Xiang, B.; Tan, W.; Zhang, J. Hydrophobic surface modification of $\mathrm{TiO}_{2}$ nanoparticles for production of acrylonitrile-styrene-acrylate terpolymer $/ \mathrm{TiO}_{2}$ composited cool materials. Appl. Surf. Sci. 2017, 419, 213-223. [CrossRef]

21. Zhang, D.; Wang, L.; Qian, H.; Li, X. Superhydrophobic surfaces for corrosion protection: A review of recent progresses and future directions. J. Coat. Technol. Res. 2016, 13, 11-29. [CrossRef]

22. Huang, J.; Wang, S.; Lyu, S. Facile Preparation of a robust and durable superhydrophobic coating using biodegradable lignin-coated cellulose nanocrystal particles. Materials 2017, 10, 1080. [CrossRef] [PubMed]

23. Jiang, S.; Guo, Z.; Liu, G.; Gyimah, K.G.; Li, X.; Dong, H. A Rapid one-step process for fabrication of biomimetic superhydrophobic surfaces by pulse electrodeposition. Materials 2017, 10, 1229. [CrossRef] [PubMed]

24. Xiang, B.; Zhang, J. Effects of content and surface hydrophobic modification of $\mathrm{BaTiO}_{3}$ on the cooling properties of ASA (acrylonitrile-styrene-acrylate copolymer). Appl. Surf. Sci. 2018, 427, 654-661. [CrossRef]

25. Ge, B.; Zhang, Z.; Zhu, X.; Men, X.; Zhou, X. A superhydrophobic/superoleophilic sponge for the selective absorption oil pollutants from water. Colloid Surf. A 2014, 457, 397-401. [CrossRef]

26. Men, X.; Shi, X.; Ge, B.; Li, Y.; Zhu, X.; Li, Y.; Zhang, Z. Novel transparent, liquid-repellent smooth surfaces with mechanical durability. Chem. Eng. J. 2016, 296, 458-465. [CrossRef]

27. Wu, H.; Zhu, K.; Cao, B.; Zhang, Z.; Wu, B.; Liang, L.; Chai, G.; Liu, A. Smart design of wettability-patterned gradients on substrate-independent coated surfaces to control unidirectional spreading of droplets. Soft Matter 2017, 13, 2995-3002. [CrossRef] [PubMed]

28. Brown, P.S.; Bhushan, B. Bioinspired, roughness-induced, water and oil super-philic and super-phobic coatings prepared by adaptable layer-by-layer technique. Sci. Rep. 2015, 5, 14030. [CrossRef] [PubMed]

29. Hoshian, S.; Jokinen, V.; Franssila, S. Robust hybrid elastomer/metal-oxide superhydrophobic surfaces. Soft Matter 2016, 12, 6526-6535. [CrossRef] [PubMed]

30. Zhou, H.; Wang, H.; Niu, H.; Zhao, Y.; Xu, Z.; Lin, T. A Waterborne coating system for preparing robust, self-healing, superamphiphobic surfaces. Adv. Funct. Mater. 2017, 27, 1604261-1604268. [CrossRef] 
31. Zhou, H.; Wang, H.; Niu, H.; Gestos, A.; Lin, T. Robust, Self-healing superamphiphobic fabrics prepared by two-step coating of fluoro-containing polymer, fluoroalkyl silane, and modified silica nanoparticles. Adv. Funct. Mater. 2013, 23, 1664-1670. [CrossRef]

32. Zhang, D.; Li, H.; Chen, X.; Qian, H.; Li, X. Effect of Surface microstructures on hydrophobicity and barrier property of anticorrosive coatings prepared by soft lithography. Adv. Mater. Sci. Eng. 2014, 2014, 7. [CrossRef]

33. Zhao, H.; Xu, J.; Jing, G.; Prieto-López, L.O.; Deng, X.; Cui, J. Controlling the localization of liquid droplets in polymer matrices by evaporative lithography. Angew. Chem. Int. Ed. 2016, 55, 10681-10685. [CrossRef] [PubMed]

34. Nokes, M.J.; Sharma, H.; Tu, R.; Kim, Y.M.; Chu, M.; Siddiqui, A.; Khine, M. Nanotextured Shrink wrap superhydrophobic surfaces by argon plasma etching. Materials 2016, 9, 196. [CrossRef] [PubMed]

35. He, Z.; Chen, Y.; Yang, J.; Tang, C.; Lv, J.; Liu, Y.; Mei, J.; Lau, W.M.; Hui, D. Fabrication of polydimethylsiloxane films with special surface wettability by $3 \mathrm{~d}$ printing. Compos. Part. B Eng. 2017, 129, 58-65. [CrossRef]

36. González Lazo, A.M.; Katrantzis, I.; Dalle Vacche, S.; Karasu, F.; Leterrier, Y. A facile in situ and uv printing process for bioinspired self-cleaning surfaces. Materials 2016, 9, 738. [CrossRef] [PubMed]

37. Xu, X.; He, Z.; Wang, Q.; Chen, F.; Fu, Q. Self-assembly of PS-b-PDMS on a tunable PDMS template with nanoscale channels and enhanced anisotropic wetting. Langmuir 2015, 31, 4605-4611. [CrossRef] [PubMed]

38. Stroj, S.; Kasemann, S.; Domke, M.; Piredda, G.; Zehetner, J.; Matylitskaya, V. Transparent superhydrophobic surfaces with high adhesion generated by the combination of femtosecond laser structuring and wet oxidation. Appl. Surf. Sci. 2017, 420, 550-557. [CrossRef]

39. Bai, H.; Du, C.; Zhang, A.; Li, L. Breath figure arrays: Unconventional fabrications, functionalizations, and applications. Angew. Chem. Int. Ed. 2013, 52, 12240-12255. [CrossRef] [PubMed]

40. Zhang, A.; Bai, H.; Li, L. Breath figure: A nature-inspired preparation method for ordered porous films. Chem. Rev. 2015, 115, 9801-9868. [CrossRef] [PubMed]

41. Böker, A.; Lin, Y.; Chiapperini, K.; Horowitz, R.; Thompson, M.; Carreon, V.; Xu, T.; Abetz, C.; Skaff, H.; Dinsmore, A.D.; et al. Hierarchical nanoparticle assemblies formed by decorating breath figures. Nature Mater. 2004, 3, 302-306. [CrossRef] [PubMed]

42. Zhang, J.; Meng, Z.; Liu, J.; Schlaich, C.; Yu, Z.; Deng, X. Breath figure lithography for the construction of a hierarchical structure in sponges and their applications to oil/water separation. J. Mater. Chem. A 2017, 5, 16369-16375. [CrossRef]

43. Widawski, G.; Rawiso, M.; Francois, B. Self-organized honeycomb morphology of star-polymer polystyrene films. Nature 1994, 369, 387-389. [CrossRef]

44. Connal, L.A.; Qiao, G.G. Honeycomb coated particles: Porous doughnuts, golf balls and hollow porous pockets. Soft Matter 2007, 3, 837-839. [CrossRef]

45. Zhang, P.; Chen, H.; Zhang, L.; Ran, T.; Zhang, D. Transparent self-cleaning lubricant-infused surfaces made with large-area breath figure patterns. Appl. Surf. Sci. 2015, 355, 1083-1090. [CrossRef]

46. Zander, N.E.; Orticki, J.A.; Karikari, A.S.; Long, T.E.; Rawlett, A.M. Super-hydrophobic surfaces via micrometer-scale templated pillars. Chem. Mater. 2007, 19, 6145-6149. [CrossRef]

47. He, Z.; Ma, M.; Xu, X.; Wang, J.; Chen, F.; Deng, H.; Wang, K.; Zhang, Q.; Fu, Q. Fabrication of superhydrophobic coating via a facile and versatile method based on nanoparticle aggregates. Appl. Surf. Sci. 2012, 258, 2544-2550. [CrossRef]

48. He, Z.; Ma, M.; Lan, X.; Chen, F.; Wang, K.; Deng, H.; Zhang, Q.; Fu, Q. Fabrication of a transparent superamphiphobic coating with improved stability. Soft Matter 2011, 7, 6435-6443. [CrossRef]

49. Wenzel, R.N. Resistance of solid surfaces to wetting by water. Ind. Eng. Chem. 1936, 28, 988-994. [CrossRef]

50. Cassie, A.B.D.; Baxter, S. Wettability of porous surfaces. Trans. Faraday Soc. 1944, 40, 546-551. [CrossRef]

51. Bussonniere, A.; Bigdeli, M.B.; Chueh, D.-Y.; Liu, Q.; Chen, P.; Tsai, P.A. Universal wetting transition of an evaporating water droplet on hydrophobic micro- and nano-structures. Soft Matter 2017, 13, 978-984. [CrossRef] [PubMed]

(C) 2018 by the authors. Licensee MDPI, Basel, Switzerland. This article is an open access article distributed under the terms and conditions of the Creative Commons Attribution (CC BY) license (http:/ / creativecommons.org/licenses/by/4.0/). 